\title{
Acute viral bronchiolitis in South Africa: Diagnostic flow
}

\author{
D A White, ${ }^{1}$ MB BCh, FC Paed (SA), MMed (Paed), Dip Allerg (SA), Cert Pulmonology (SA) Paed; H J Zar, ${ }^{2}$ MB BCh, FC Paed (SA), PhD; \\ S A Madhi, ${ }^{3}$ MB BCh, MMed (Paed), FC Paed (SA), PhD; P Jeena, ${ }^{4}$ MB ChB, FC Paed (SA), Cert Pulmonology (SA) Paed; \\ B Morrow, ${ }^{5}$ BSc (Physio), PG Dipl Health Research Ethics, PhD; R Masekela, ${ }^{4}$ MB BCh, MMed (Paed), Cert Pulmonology (SA) Paed, \\ Dip Allerg (SA), FCCP, PhD; S Risenga, ${ }^{6} \mathrm{MB}$ ChB, FC Paed (SA), Dip Allerg (SA), Cert Pulmonology (SA) Paed; R J Green, ${ }^{7} \mathrm{PhD}$, DSc

\begin{abstract}
' Department of Paediatrics and Child Health, Faculty of Health Sciences, University of the Witwatersrand, Johannesburg, South Africa
${ }^{2}$ Department of Paediatrics and Child Health, Red Cross War Memorial Children's Hospital, and MRC Unit on Child and Adolescent Health, Faculty of Health Sciences, University of Cape Town, South Africa

${ }^{3}$ Medical Research Council: Respiratory and Meningeal Pathogens Research Unit, University of the Witwatersrand, Johannesburg, South Africa

${ }^{4}$ Department of Paediatrics and Child Health, Faculty of Health Sciences, University of KwaZulu-Natal, Durban, South Africa

${ }^{5}$ Department of Paediatrics and Child Health, Faculty of Health Sciences, University of Cape Town, South Africa

${ }^{6}$ Department of Pulmonology, Faculty of Health Sciences, University of Limpopo, Polokwane, and Pietersburg Hospital, South Africa

${ }^{7}$ Department of Paediatrics and Child Health, Faculty of Health Sciences, University of Pretoria, and Steve Biko Academic Hospital, Pretoria,
\end{abstract} \\ South Africa
}

Corresponding author: D A White (debbie.white@wits.ac.za)

Bronchiolitis may be diagnosed on the basis of clinical signs and symptoms. In a young child, the diagnosis can be made on the clinical pattern of wheezing and hyperinflation.

Clinical symptoms and signs typically start with an upper respiratory prodrome, including rhinorrhoea, low-grade fever, cough and poor feeding, followed 1 - 2 days later by tachypnoea, hyperinflation and wheeze as a consequence of airway inflammation and air trapping.

The illness is generally self limiting, but may become more severe and include signs such as grunting, nasal flaring, subcostal chest wall retractions and hypoxaemia. The most reliable clinical feature of bronchiolitis is hyperinflation of the chest, evident by loss of cardiac dullness on percussion, an upper border of the liver pushed down to below the 6th intercostal space, and the presence of a Hoover sign (subcostal recession, which occurs when a flattened diaphragm pulls laterally against the lower chest wall).

Measurement of peripheral arterial oxygen saturation is useful to indicate the need for supplemental oxygen. A saturation of $<92 \%$ at sea level and $90 \%$ inland indicates that the child has to be admitted to hospital for supplemental oxygen. Chest radiographs are generally unhelpful and not required in children with a clear clinical diagnosis of bronchiolitis.

Blood tests are not needed routinely. Complete blood count tests have not been shown to be useful in diagnosing bronchiolitis or guiding its therapy. Routine measurement of C-reactive protein does not aid in management and nasopharyngeal aspirates are not usually done. Viral testing adds little to routine management.

Risk factors in patients with severe bronchiolitis that require hospitalisation and may even cause death, include prematurity, congenital heart disease and congenital lung malformations.

S Afr Med J 2016;106(4):328-329. DOI:10.7196/SAMJ.2016.v106i4.10441

\section{Clinicall manifestations}

Bronchiolitis is a viral-induced lower respiratory tract infection that occurs predominantly in children $<2$ years of age, particularly infants. Many viruses have been proven or attributed to cause bronchiolitis, including and most commonly the respiratory syncytial virus (RSV) and rhinovirus. Bronchiolitis may be diagnosed on the basis of clinical signs and symptoms. In a young child, the diagnosis can be made on the clinical pattern of wheezing and hyperinflation.

Clinical symptoms and signs typically start with an upper respiratory prodrome, including rhinorrhoea, low-grade fever, cough and poor feeding, followed 1 - 2 days later by tachypnoea, hyperinflation and wheeze as a consequence of airway inflammation and air trapping. ${ }^{[1]}$ The illness is generally self limiting, but may progressively become more severe and include signs such as grunting, nasal flaring, subcostal chest wall retractions and hypoxaemia. ${ }^{[2]}$ The most reliable clinical feature of bronchiolitis is hyperinflation of the chest, evident by loss of cardiac dullness on percussion, an upper border of the liver pushed down to below the 6th intercostal space, and the presence of a Hoover sign (subcostal recession, which occurs when a flattened diaphragm pulls laterally against the lower chest wall).
Measurement of peripheral arterial oxygen saturation is useful to indicate the need for supplemental oxygen. A saturation of $<92 \%$ at sea level and $90 \%$ inland indicates that the child requires hospital admission for supplemental oxygen.

\section{Investigations}

\section{Chest radiographs}

Chest radiographs (CXRs) are generally unhelpful and not required in children with a clear clinical diagnosis of bronchiolitis.

Risk of airspace disease appears to be particularly low in children with saturation $>92 \%$ and with mild to moderate distress. ${ }^{[3]} \mathrm{A}$ temperature $\geq 38^{\circ} \mathrm{C}$ has been shown to be a clinical predictor of radiographic abnormalities. ${ }^{[4]}$

CXRs in bronchiolitis show signs of hyperinflation, peribronchial thickening or patchy areas of consolidation and collapse, which may be confused with signs of pneumonia. A CXR should only be done in the following instances: ${ }^{[2,4,5]}$

- if complications are suspected, e.g. pleural effusion or pneumothorax

- severe cases

- temperature $\geq 38^{\circ} \mathrm{C}$ 
- uncertain diagnosis

- if the child fails to improve or if their condition deteriorates.

\section{Haematology}

Blood tests are not needed routinely. Complete blood count tests have not been shown to be useful in diagnosing bronchiolitis or guiding its therapy. ${ }^{[2]}$ Routine measurement of C-reactive protein does not aid in management. ${ }^{[6]}$

If the infant appears severely ill, consider alternative diagnoses (bacterial co-infection and other causes of airway obstruction) Clinical signs of concern include pallor, lethargy, severe tachycardia, high temperature, hypotonia or seizures. In cases of serious sepsis investigations may include a CXR, blood culture, and urinary and cerebrospinal fluid analysis. ${ }^{[5]}$

\section{Nasopharyngeal aspirates}

Nasopharyngeal aspirates (NPAs) are not usually taken and viral testing adds little to routine management, ${ }^{[7]}$ but NPAs are needed to inform surveillance, measuring burden of disease and also in the following cases: ${ }^{[5,7]}$

- neonates ( $<1$ month)

- history of apnoea with illness

- bed management to allow cohorting of patients.

NPAs should be immersed in viral transport medium at $4-8^{\circ} \mathrm{C}$ and transported to an appropriate laboratory within 72 hours of collection. Specimens should be tested by multiplex real-time reverse-transcription polymerase chain reaction (rRT-PCR) assay for respiratory viruses. Comparative studies have shown that rRT-PCR assays are substantially more sensitive than conventional methods, such as viral culture and immunofluorescence assays, for detecting respiratory viruses. ${ }^{[8]}$

Furthermore, multiplex rRT-PCR has a significant advantage, as it permits simultaneous amplification of several viruses in a single reaction, facilitating a cost-effective diagnosis..$^{[8}$

\section{Risk factors for severe disease}

In infants and young children respiratory viruses have the propensity to produce more serious lower respiratory tract illnesses, bronchiolitis and pneumonia. Infants $<1$ year of age are at greatest risk of bronchiolitis, and the disease is more severe when risk factors are present (Table 1). ${ }^{[9-15]}$

Debate about the importance of respiratory syncytial virus infection as a cause of hospitalisation in late preterm infants has raged because of the cost of prophylactic therapy. Recent reports have suggested that these infants are at equal risk and require prophylaxis. ${ }^{[16,17]}$

South African studies have revealed that the mean duration of symptoms following bronchiolitis was 12 days (95\% confidence interval 11 - 14 days). After 21 and 28 days, $18 \%$ and $9 \%$, respectively, were still ill. Thirty-four percent of these children were seen by a physician during an unscheduled visit. ${ }^{[18]}$

Finally, the respiratory viruses, especially RSV, may predispose to recurrent episodes of wheezing and possibly asthma. ${ }^{[19,20]}$

Table 1. Risk factors for severe bronchiolitis, requiring hospitalisation or causing mortality

Premature infants

Congenital heart disease

Congenital lung malformations

Chronic lung disease

Neuromuscular disease

Age $<6$ months

Male sex

Siblings living in the household

Daycare attendance

Exposure to tobacco smoke Immune compromise (malignancy, primary immunodeficiency, $\left.\mathrm{HIV}^{\star}\right)$

${ }^{*}$ Risk greatest for pneumonia.

Table 2. Differential diagnosis of bronchiolitis

\begin{tabular}{l}
\hline Acute symptoms \\
Bronchopneumonia \\
Pertussis \\
Foreign body \\
Myocarditis \\
Recurrent wheeze \\
Cystic fibrosis \\
Cardiac disease \\
HIV/tuberculosis
\end{tabular}

\section{Differential diagnosis}

The differential diagnosis of respiratory symptoms is wide, but where hyperinflation and wheeze occur the conditions listed in Table 2 should be considered.

\section{References}

1. Wohl MEB. Bronchiolitis. In: Chernick V, Boat TF, Wilmot RW, Bush A, eds. Kendig's Disorders of the Respiratory Tract in Children. Philadelphia: Saunders, 2006:423-432. DOI:10.1016/ B978-0-7216-3695-5.50029-8

2. American Academy of Pediatrics Subcommittee on Diagnosis and Management of Bronchiolitis. Diagnosis and management of bronchiolitis. Pediatrics 2006;118(4):1774-1793. DOI:10.1542/ peds.2006-222

3. Schuh S, Lalani A, Allen U, et al. Evaluation of the utility of radiography in acute bronchiolitis. J Pediatr 2007;150:429-433. DOI:10.1016/j.jpeds.2007.01.005

4. Ecochard-Dugelay E, Beliah M, Perreaux F, et al. Clinical predictors of radiographic abnormalities among infants with bronchiolitis in a pediatric emergency department. BMC Pediatrics 2014;14:143. DOI:10.1186/1471-2431-14-143

5. Gavin R, Sheperd M. Starship Clinical Guideline. http:// www.adhb.govt.nz/starshipclinicalguidelines/_Documents/ Bronchiolitis.pdf (accessed 15 May 2015).

6. Moodley T, Masekela R, Kitchin O, Risenga S, Green RJ. Acute viral bronchiolitis. Aetiology and treatment implications in a population that may be HIV co-infected. S Afr J Epidemiol Infect 2010;25(2):6-8.

7. Zorc JJ, Hall CB. Bronchiolitis: Recent evidence on diagnosis and management. Pediatrics 2010;125:342-349. DOI:10.1542/ peds.2009-2092

8. Pretorius MA, Madhi SA, Cohen C, et al. Respiratory viral coinfections identified by a 10-plex real-time reverse-transcription polymerase chain reaction assay in patients hospitalized with severe acute respiratory illness - South Africa, 2009 - 2010. J Infect Dis 2012;206(S1):S159-S165. DOI: 10.1093/infdis/jis538

9. Stein RT, Sherill D, Morgan WJ, et al. Respiratory syncytial virus in early life and risk of wheeze and allergy by age 13 years. Lancet 1999:354:541-545. DOI:10.1016/S0140-6736(98) 10321-5

10. Dominquez-Pinilla N, Belda Hofheinz S, Vivanco Martinez JL, et al. Respiratory syncytial virus in immunocompromised patients in a pediatric hospital: 5 years experience. An Pediatr (Barc) 2015;82(1):35-40. DOI:10.1016/.anpedi.2014.04.016

11. Cohen C, Walaza S, Moyes J, et al. Epidemiology of viral-associated acute lower respiratory tract infection among children $<5$ years of age in a high HIV prevalence setting, South Africa, 2009 - 2012. Pediatr Infect Dis J 2015;34:66-72. DOI:10.1097/INF.0000000000000478

12. Schuster JE, Williams JV. Human metapneumovirus. Pediatr Rev 2013;34:558-565. DOI:10.1542/pir.34-12-558

3. Asner S, Stephens D, Pedulla P, Richardson SE, Robinson J, Allen U. Risk factors and outcomes for respiratory syncytial virusrelated infections in immunocompromised children. Pediatr Infect Dis J 2013;32:1073-1076. DOI:10.1097/INF.0b013e31829dff4

14. Moyes J, Cohen C, Pretorius M, et al. Epidemiology of respiratoyes s, Cohen C, Pretoris M, et al. Epideniology of respiratory syncytial virus-associated acute lower respiratory tract uninfected South African children, 2010-2011. J Infect Dis uninfected South Arican children, 2010 2011. J Infect D

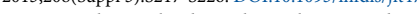

15. Tempia S, Walaza S, Viboud C, et al. Mortality associated with seasonal and pandemic influenza and respiratory syncytial virus among children $<5$ years of age in a high HIV prevalence setting - South Africa, 1998 2009. Clin Infect Dis 2014;58:1241-1249. DOI:10.1093/cid/ciu095

16. Resch B, Paes B. Are late preterm infants as susceptible to RSV infection as full term infants? Early Hum Dev 2011;87(Suppl 1):S47-S49. DOI:10.1016/j.earlhumdev.2011.01.010

17. Madhi SA, Venter M, Alexandra R, et al. Respiratory syncytial virus associated illness in high-risk children and national characterisation of the circulating virus genotype in South Africa. J Clin Virol 2003;27:180-189.

18. Swingler GH, Hussey GD, Zwarenstein M. Duration of illness in ambulatory children diagnosed with bronchiolitis. Arch Pediatr Adolesc Med 2000;154:997-1000. DOI:10.1001/ archpedi.154.10.997

19. Sigurs N, Gustafsson PM, Bjarnason R, et al. Severe respiratory syncytial virus bronchiolitis in infancy and asthma and allergy by age 13 years. Am J Respir Crit Care Med 2005;171:137-141. DOI: $10.1164 / \mathrm{rccm} .200406-730 \mathrm{OC}$

20. Lotz MT, Moore ML, Peebles RS Jr. Respiratory syncytial virus and reactive airway disease. Curr Top Microbiol Immunol 2013;372:105-118. DOI:10.1007/978-3-642-38919-1_5 